\title{
Metabolic and electrolyte abnormalities as risk factors in drug-induced long QT syndrome
}

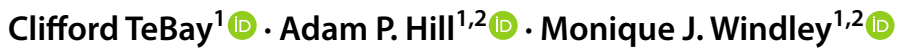

Received: 10 December 2021 / Accepted: 4 January 2022 / Published online: 27 January 2022

(c) The Author(s) 2022

\begin{abstract}
Drug-induced long QT syndrome (diLQTS) is the phenomenon by which the administration of drugs causes prolongation of cardiac repolarisation and leads to an increased risk of the ventricular tachycardia known as torsades de pointes (TdP). In most cases of diLQTS, the primary molecular target is the human ether-à-go-go-related gene protein (hERG) potassium channel, which carries the rapid delayed rectifier current $\left(\mathrm{I}_{\mathrm{Kr}}\right)$ in the heart. However, the proarrhythmic risk associated with drugs that block hERG can be modified in patients by a range of environmental- and disease-related factors, such as febrile temperatures, alterations in $\mathrm{pH}$, dyselectrolytaemias such as hypokalaemia and hypomagnesemia and coadministration with other drugs. In this review, we will discuss the clinical occurrence of drug-induced LQTS in the context of these modifying factors as well as the mechanisms by which they contribute to altered hERG potency and proarrhythmic risk.
\end{abstract}

Keywords Arrhythmia $\cdot \mathrm{hERG} \cdot$ Hypokalaemia $\cdot$ Hypomagnesemia $\cdot$ Febrile $\cdot$ Acidosis

\section{Drug-induced long QT syndrome}

Drug-induced (diLQTS) or acquired long QT syndrome (aLQTS) is characterised by prolongation of the QT interval on the surface electrocardiogram (ECG) and is associated with a markedly increased risk of the potentially lethal ventricular arrhythmia known as torsades de pointes (TdP (Roden 2004)). A prospective study of hospital admission for drug-induced TdP reported 3.3 cases per million over the 4-week study period, translating to an annual incidence of 4/100,000 (Darpö 2001). However, this may be an underestimate for the broader population since TdP is often not reported in out-of-hospital cases (Birda et al. 2018; Lin et al. 2020; Yu et al. 2017). For hospitalised patients, the prevalence of severe diLQTS has been reported as between 1.6 and 3.3\% of patients (Birda et al. 2018; Lin et al. 2020; Yu et al. 2017), with these patients having a higher all-cause mortality than their non-LQTS counterparts (Lin et al. 2020; Yu et al. 2017). Over the past 30 years, a range of cardiac

Monique J. Windley

m.windley@victorchang.edu.au

1 Victor Chang Cardiac Research Institute, 405, Liverpool street, Darlinghurst, Sydney, NSW 2020, Australia

2 St. Vincent's Clinical School, UNSW Sydney, Sydney, Australia
(Kannankeril et al. 2011; Selzer and Wray 1964; Singh et al. 2000) and noncardiac (Schoonmaker et al. 1966) drugs have been shown to prolong the QT interval, with several being recalled from the market (Roden 2004). diLQTS can be caused by drugs that block any of the ion channel currents that contribute to normal cardiac repolarisation. In practice, however, the majority of drugs that cause diLQTS do so by inhibiting hERG/Kv11.1 potassium channels, encoded by the $\mathrm{KCNH} 2$ gene, which carries the rapid delayed rectifier $\mathrm{K}^{+}$current $\left(\mathrm{I}_{\mathrm{Kr}}\right)$ in the heart (Vandenberg et al. 2012). This unintentional block of hERG is therefore a problem both for development of new therapeutic compounds, as well as management of patients prescribed such drugs (see Table 1 for a full list of compounds discussed in this review). Consequently, screening for potency of hERG channel block, as a surrogate for QT prolongation and repolarisation delay, is a mandated part of preclinical drug development ((ICH S7B 2005), Fig. 1). However, the link between a drug's potency to block hERG and the emergence of arrhythmia is complex. Of the majority of new chemical entities, up to $70 \%$ in some estimates (Shah 2005) can block hERG at some concentration, yet only a small percentage cause arrhythmia (Darpö 2001, 2007). Moreover, even for drugs that are demonstrably "high risk", the severity of adverse events across the patient population can be highly variable ranging from minimal prolongation of cardiac repolarisation to the induction of lethal 
Table 1 Compounds related to TdP development. List of all compounds mentioned in this literature review, their drug class and primary target

\begin{tabular}{|c|c|c|c|}
\hline Drug name & Drug class & Primary target & Reference \\
\hline Amiodarone & Class III antiarrhythmic & hERG and CACNA2D $2 *$ channel & Du et al. (2011) \\
\hline Amisulpride & Antipsychotic & Dopamine D2 receptor & Lin et al. (2009) \\
\hline Astemizole & Antihistamine & Histamine $\mathrm{H} 1$ receptor & Yao et al. (2005) \\
\hline Azimilide & Class III antiarrhythmic & $\mathrm{I}(\mathrm{Ks})$ and hERG channels & Busch et al. (1998), Dong et al. (2004) \\
\hline Azithromycin & Macrolide antibiotic & $23 \mathrm{~s}$ RNA of the bacterial 50S ribosomal unit & $\begin{array}{l}\text { Delaunois et al. (2021), TeBay et al. (2021), } \\
\text { Zequn et al. (2021) }\end{array}$ \\
\hline Bepridil & Antianginal & $\begin{array}{l}\text { L-type calcium channel and } \mathrm{Na}^{+} / \mathrm{K}^{+} \text {-ATPase } \\
\text { pump }\end{array}$ & Windley et al. (2018) \\
\hline Berberine & Alkaloid & Unknown & Zhi et al. (2015) \\
\hline Ceftriaxone & Cephalosporin antibiotic & $\begin{array}{l}\text { Peptidases of the bacterial cytoplasmic } \\
\text { membrane }\end{array}$ & Lazzerini et al. (2018) \\
\hline Chloroquine & Antimalarial & Hemozoin & $\begin{array}{l}\text { Delaunois et al. (2021), TeBay et al. (2021), } \\
\text { Warhurst (1986), Warhurst et al. (2003), } \\
\text { Zequn et al. (2021) }\end{array}$ \\
\hline Cisapride & Gastroprokinetic & Serotonin $5-\mathrm{HT}_{4}$ receptor & $\begin{array}{l}\text { Barrows, et al. (2009), Kamiya et al. (2008), } \\
\text { Lacerda et al. (2001), Lee et al. (2019), Lin } \\
\text { et al. (2005c), Perrin et al. (2008), Thomas } \\
\text { et al. (1998), Thouta et al. (2018), Windley } \\
\text { et al. (2016), Windley et al. (2018) }\end{array}$ \\
\hline Clarithromycin & Macrolide antibiotic & $23 \mathrm{~s}$ RNA of the bacterial 50S ribosomal unit & Zhi et al. (2015) \\
\hline Diltiazem & Antianginal & L-type calcium channel & Thomas et al. (1998) \\
\hline Disopyramide & Class $1 \mathrm{~A}$ antiarrhythmic & Fast sodium channels & Hirose et al. (2008), Lazzerini et al. (2018) \\
\hline Dofetilde & Class III antiarrhythmic & hERG channel & $\begin{array}{l}\text { Du et al. 2011, Perrin et al. (2008), Singh } \\
\text { et al. (2000), Wang et al. (2016), West et al. } \\
\text { (1997), Yang et al. (2004) }\end{array}$ \\
\hline Domperidone & Gastroprokinetic & Dopamine D2 and D3 receptor & Boyce et al. (2012) \\
\hline E-4031 & Class III antiarrhythmic & hERG channel & $\begin{array}{l}\text { Wang et al. (1997), West et al. (1997), Yao } \\
\text { et al. (2005) }\end{array}$ \\
\hline Enalapril & Antihypertensive & Angiotensin converting enzyme & Varriale and Ramaprasad (1995) \\
\hline Encainide & Class 1c antiarrhythmic & Sodium channel protein type 5 subunit alpha & Echt et al. (1991) \\
\hline Erythromycin & Macrolide antibiotic & $23 \mathrm{~s}$ RNA of the bacterial $50 \mathrm{~S}$ ribosomal unit & $\begin{array}{l}\text { Delaunois et al. (2021), Guo et al. (2005), } \\
\text { Kirsch et al. (2004), Lacerda et al. (2001), } \\
\text { Paris et al. (1994) }\end{array}$ \\
\hline Fentanyl & Opioid analgesic & $\mu$-opioid receptor & Tschirhart and Zhang (2020) \\
\hline Flecainide & Class $1 \mathrm{C}$ antiarrhythmic & Fast sodium channel & $\begin{array}{l}\text { Du et al. (2011), Echt et al. (1991), Paul et al. } \\
\text { (2002) }\end{array}$ \\
\hline Flupenthixol & Antipsychotic & Dopamine D1 and D2 receptor & Lin et al. (2009) \\
\hline Gentamicin & Aminoglycoside antibiotic & $\begin{array}{l}\text { Lipopolysaccharides and phospholipids and } \\
\text { the bacterial cell membrane }\end{array}$ & Varriale and Ramaprasad (1995) \\
\hline Glyburide & Sulfonylurea & $\mathrm{KATP}^{* *}$ channels & Varriale and Ramaprasad (1995) \\
\hline Halofantrine & Antimalarial & Unknown & Charbit et al. (2002) \\
\hline Haloperidol & Antipsychotic & Dopamine D2 receptor & Lin et al. (2009) \\
\hline Hydroxychloroquine & Antimalarial & Unknown & $\begin{array}{l}\text { Delaunois et al. (2021), TeBay et al. (2021), } \\
\text { Warhurst et al. (2003), Zequn et al. (2021) }\end{array}$ \\
\hline Ibutilide & Class III antiarrhythmic & hERG and slow sodium channel & Lin et al. (2008) \\
\hline Ibogaine & Psychoactive/psychedelic & $\begin{array}{l}\mu-, \delta \text { - and } \kappa-\text { opioid receptors, serotonin } \\
5-\mathrm{HT}_{2 \mathrm{~A}}, \mathrm{HT}_{2 \mathrm{C}} \text { and } \mathrm{HT}_{3-} \text { receptors, sigma } \\
\sigma_{1} \text { and } \sigma_{2} \text { receptors, NMDA*** receptor, } \\
\text { nicotinic acetylcholine (nACh) receptor, } \\
\text { serotonin transporter (SERT) and dopa- } \\
\text { mine active transporter (DAT) }\end{array}$ & Thurner et al. (2014) \\
\hline Itraconazole & Antifungal & $\begin{array}{l}\text { 14- } \alpha \text {-sterol demethylase of the fungal cell } \\
\text { membrane }\end{array}$ & Pohjola-Sintonen et al. (1993) \\
\hline
\end{tabular}


Table 1 (continued)

\begin{tabular}{|c|c|c|c|}
\hline Drug name & Drug class & Primary target & Reference \\
\hline Ketoconazole & Antifungal & $\begin{array}{l}\text { 14- } \alpha \text {-sterol demethylase of the fungal cell } \\
\text { membrane }\end{array}$ & $\begin{array}{l}\text { Boyce et al. (2012) Rajput et al. (2010), Yao } \\
\text { et al. (2005) }\end{array}$ \\
\hline Lopinavir & Antiretroviral & HIV-1 protease enzyme & Zequn et al. (2021) \\
\hline Loratadine & Antihistamine & H1 histamine receptor & Lacerda et al. (2001) \\
\hline Moxifloxacin & Fluoroquinolone antibiotic & $\begin{array}{l}\text { Topoisomerase II (DNA gyrase) and topoi- } \\
\text { somerase IV of the bacteria }\end{array}$ & Alexandrou et al. (2006) \\
\hline Posaconazole & Antifungal & $\begin{array}{l}14-\alpha \text {-sterol demethylase of the fungal cell } \\
\text { membrane }\end{array}$ & Panos et al. (2016) \\
\hline Prednisolone & Glucocorticoid & Phospholipase A2 & Hirose et al. (2008) \\
\hline Quinidine & Class I antiarrhythmic & $\begin{array}{l}\text { L-type calcium, hERG, slow IKs and } \\
\text { KATP** channels }\end{array}$ & $\begin{array}{l}\text { Ayad et al. (2010), Barrows et al. (2009), } \\
\text { Dong et al. (2004), Paul et al. (2002), Po } \\
\text { et al. (1999), Roden et al. (1986), Selzer and } \\
\text { Wray, (1964), Yang et al. (1997) }\end{array}$ \\
\hline Quinine & Alkaloid/antimalarial & Unknown & Warhurst (1986) \\
\hline Risperidone & Antipsychotic & $\begin{array}{l}\text { Dopaminergic D2 and serotonin } 5-\mathrm{HT}_{2 \mathrm{~A}} \\
\text { receptors }\end{array}$ & Lin et al. (2009) \\
\hline Ritonavir & Antiretroviral & HIV protease inhibitor & Zequn et al. (2021) \\
\hline Terfenadine & Antihistamine & Histamine H1-receptor & $\begin{array}{l}\text { Kamiya et al. (2008), Lacerda et al. (2001), } \\
\text { Paris et al. (1994), Perrin et al. (2008), } \\
\text { Pohjola-Sintonen et al. (1993), Rajput et al. } \\
\text { (2010), Thouta et al. (2018), Windley et al. } \\
\text { (2018), Yao et al. (2005) }\end{array}$ \\
\hline Thioridazine & Antipsychotic & Dopamine D1 and D2 receptors & Schoonmaker et al. (1966) \\
\hline Vancomycin & Glycopeptide antibiotic & $\begin{array}{l}\text { Peptidoglycan matrix inhibitor of the bacte- } \\
\text { rial cell membrane }\end{array}$ & Varriale and Ramaprasad (1995) \\
\hline Verapamil & Class IV antiarrhythmic & L-type calcium channel & Windley et al. (2018), Zhang et al. (1999) \\
\hline
\end{tabular}

${ }^{*}$ Calcium voltage-gated channel auxiliary subunit alpha2 delta2 gene protein.**ATP-sensitive $\mathrm{K}^{+}$channel.***N-methyl-D-aspartate receptor

arrhythmia (Kannankeril et al. 2011; Singh et al. 2000). A number of factors likely contribute to this variable response, including pre-existing disease resulting in electrical or structural remodelling of the myocardium, sex differences and an a

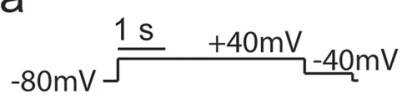

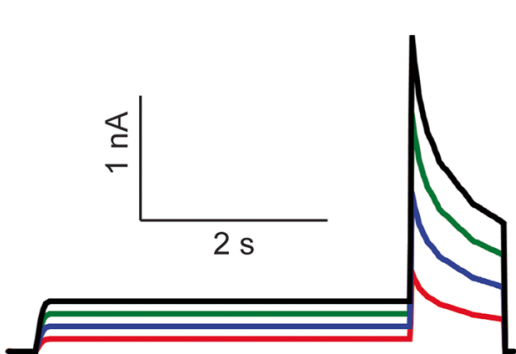

Fig. 1 Summary of environmental effects on drug potency. Many disease factors are known to shift the potency of drugs blocking hERG, such as fever, hypokalaemia, hypocalcaemia, etc. a A theoretical hERG tail current with scale indicated for current amplitude and time, as elicited by the protocol in the above insert. The black trace represents a control current evoked in drug-free conditions, with the blue trace representing $50 \%$ inhibition of the current evoked by a theoretical drug. A condition leading to less potent drug inhibition is represented in green, showing only $25 \%$ inhibition, with a condition

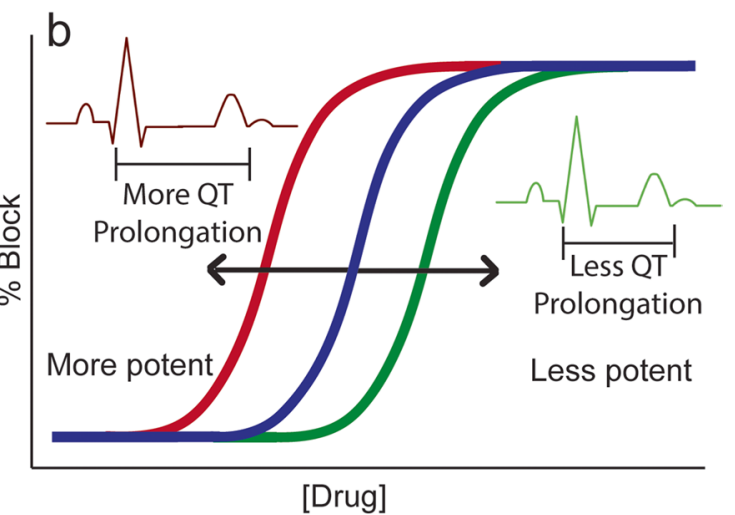

leading to greater potency leading to $75 \%$ inhibition and as depicted in red. $\mathbf{b}$ A theoretical concentration response curve, with the main drug effect represented in blue. A condition creating lesser potency would lead to a rightward shift, as indicated in green, and, on an ECG, would lead to less QT prolongation, as seen in the insert and depicted in green. Conditions leading to greater potency are depicted in red, and would shift leftward and, on an ECG, would lead to more prolongation, as seen in the insert and as depicted in red. Assets for the ECG traces obtained from Servier Medical Art (Servier 2021) 
individual's genetic background (Echt et al. 1991; Makkar et al. 1993; Roden and Viswanathan 2005). Aside from these patient-specific factors, a drug's proarrhythmic propensity can also be modified by other systemic/acquired factors in patients such as electrolyte disturbances, acidosis, febrile temperatures and coadministration with other drugs. The importance of such considerations has been highlighted recently in relation to repurposing of drugs for treatment of COVID-19. Specifically, various combinations of drugs that are known to carry some degree of proarrhythmic risk, including chloroquine, hydroxychloroquine, azithromycin, erythromycin and lopinavir/ritanavir, have been proposed as potential therapies (Delaunois et al. 2021; Zequn et al. 2021) in COVID-19 patients where fever (Aslam et al. 2021; Pan et al. 2020; Zhou et al. 2020), acidosis (Zhou et al. 2020) and electrolyte disturbances (Alfano et al. 2021; Lippi et al. 2020; Stevens et al. 2021) were also reported. Here, we will review both the clinical occurrence of diLQTS in the context of fever, hypokalaemia, hypomagnesemia and other electrolyte disturbances and the mechanisms by which these factors contribute to altered potency of hERG block and proarrhythmic risk.

\section{Effect of kalaemic variation on drug-induced long QT syndrome}

Potassium is the most abundant intracellular cation, which in healthy patients exists within the range of $3.6-5.0 \mathrm{mM}$ in the plasma (El-Sherif and Turitto 2011; Salzman 2018). In the case of altered serum potassium, hypokalaemia is the most common electrolyte abnormality, occurring in over $20 \%$ of hospitalised patients, and is defined as a plasma $\mathrm{K}^{+}$ level of less than $3.6 \mathrm{mM}$. This occurs most frequently as a result of decreased intake, increased renal or gastrointestinal loss or via transcellular shift (El-Sherif and Turitto 2011; Salzman 2018). Hyperkalaemia (plasma $\mathrm{K}^{+}>5.0 \mathrm{mM}$ ) is less common, reported in $8 \%$ of hospitalised patients, and occurs as a result of potassium-sparing diuretic use, higher intake, decreased excretion due to renal failure or damage or transcellular shift of potassium into the extracellular environment (El-Sherif and Turitto 2011; Salzman 2018). In patients taking drugs with established proarrhythmic risk, changes in serum $\mathrm{K}^{+}$have been observed to drive further QT prolongation and incidence of TdP. For example, Ayad et al. reported the case of a patient taking quinidine for 15 years without any incidence of QT prolongation who developed TdP and syncope as a result of hypokalaemia by way of gastrointestinal loss (Ayad et al. 2010). Similarly, in a study of 24 individuals, patients administered hERG blockers such as quinidine while taking potassium-depleting diuretics were identified to be at higher risk for QT prolongation and development of TdP, although some of these patients also presented with several other risk factors such as hypertension, cardiomyopathy or were also taking additional QT prolonging drugs (Roden et al. 1986). However, hypokalaemia rarely presents alone, meaning other parallel factors can also contribute to QT prolongation. In a study of 11 patients in whom diLQTS was present, including 8 who exhibited severe hypokalaemia, additional factors such as hypomagnesaemia, hypertension and alcohol use were also present (Digby et al. 2011), while in a larger study of 804 chronic kidney disease patients, lower serum $\mathrm{K}^{+}$and $\mathrm{Ca}^{2+}$ were each found to be significant contributors to QT prolongation, often against a background of chronic diseases such as hypertension or diabetes (Liu et al. 2019).

\section{Mechanism of kalaemia-dependent changes in hERG block and QT prolongation}

Understanding the relationship between kalaemic variation and drug-induced prolongation of repolarization is complex, since variation in extracellular potassium has direct effects on cardiac repolarization, via effects on potassium channel function and expression, as well as drug binding (Barrows et al. 2009; Guo et al. 2009, 2011; Limberis et al. 2006; Melgari et al. 2014; West et al. 1997; Yang et al. 2004, 1997). Here we will focus on studies that have specifically addressed potassium dependence of a drug's potency to block hERG. Across the literature, reports of the influence of $\mathrm{K}^{+}$on potency to block hERG across drugs is broadly consistent, with increasing extracellular potassium reducing the potency of block (Barrows et al. 2009; Busch et al. 1998; Lin et al. 2007, 2008, 2005c; Lin and Papazian 2007; Mergenthaler et al. 2001; TeBay et al. 2021; Wang et al. 1997; West et al. 1997; Yang et al. 2004) and decreased potassium concentration increasing potency of block (Lin et al. 2005a; TeBay et al. 2021; Tschirhart and Zhang 2020). Two potential mechanisms have been proposed to explain this. First, it has been suggested that changes in the state or conformation of $\mathrm{hERG}$ as a function of $\mathrm{K}^{+}$might impact the potency of drugs that exhibit state-dependent binding. The hERG channel can exist in one of three states: closed, open or inactivated, with two voltage-dependent gates, a fast inactivation gate and a slow activation/deactivation gate (Vandenberg et al. 2012). Some drugs can exhibit "state preference", showing a greater affinity for either open or inactivated state (Lee et al. 2016, 2019; Perrin et al. 2008; Stork et al. 2007). As a result, changes in conditions such as $\mathrm{K}^{+}$that is known to alter the equilibrium between the open and inactivated states of the channel can contribute to variation in observed potency for state-dependent drugs. For example, after observing reduced potency across a panel of drugs with inactivated state preference in the presence of elevated $\mathrm{K}^{+}$, Yang et al. posited that the shift away from the inactivated state of the hERG channel that occurs under these conditions 
(Fig. 2a) would reduce the observed degree of block (Yang et al. 2004). Supporting this idea, it has also been shown (in the absence of variation of external $\mathrm{K}^{+}$) that hERG mutants with reduced inactivation could greatly attenuate the block of drugs with inactivated state preference such as cisapride and terfenadine (Perrin et al. 2008), while voltage protocols that drive occupancy of the inactivated state result in a higher observed potency for state-dependent drugs (Lee et al. 2016, 2019). However, there is also evidence to counter the concept of state-dependent binding underlying the effect of potassium. Barrows et al. showed that despite significant reduction in hERG potency for cisapride and quinidine with increasing $\mathrm{K}^{+}$between 0 and $20 \mathrm{mM} \mathrm{K}^{+}$, there was little change in the fraction of channels existing in inactivated state at $+20 \mathrm{mV}$ between these two potassium concentrations. Based on this evidence, they reasoned that state preference of block did not underpin the altered potency seen for these drugs (Barrows et al. 2009). Similarly, though again outside of a $\mathrm{K}^{+}$context, Thouta et al. used mutants that were constitutively open to explore the preference of terfenadine or cisapride for binding to the open or inactivated state and were able to show that degree of drug block did not change in accordance with the extent of inactivation, suggesting that these two drugs do not exhibit an inactivation state preference (Thouta et al. 2018).

The second mechanism proposed to explain the potassium dependence of a drug's potency to block hERG is that electrostatic repulsion between the $\mathrm{K}^{+}$ion and the bound drug molecule induces a "knock-off" effect (Barrows et al. 2009; Wang et al. 1997). Wang et al. showed that an inactivationdeficient mutant (S631C, G628C) had near identical external $\mathrm{K}^{+}$sensitivity for E-4031 block as the wild-type channel (Wang et al. 1997) and proposed that since both potassium and E-4031 possess a single positive charge, an electrostatic repulsion mechanism could explain the effect of potassium on drug potency. The study found that with the differences in $\mathrm{K}^{+}$they had used ( $2 \mathrm{mM}$ vs $98 \mathrm{mM}$ ), there would be sufficient free energy to account for the observed reduction in block (Wang et al. 1997). Further to this, it has been proposed that the ability of monovalent cations to "knock off" a drug from its binding site on the hERG channel depends on the ion's permeability (Barrows et al. 2009). Evidence for this includes a correlation between the observed degree of potency of block for cisapride and quinidine and ionic permeability when the permeant ion or chemical species is switched between potassium, rubidium, caesium and TEA, where the degree of block follows the ion's permeability through hERG of $P_{\mathrm{K}+}=P_{\mathrm{Rb}+}>P_{\mathrm{Cs}+}>>P_{\mathrm{TEA}}$ (Barrows et al. 2009). However, sensitivity of block to specific monovalent ions is also drug dependent, as the degree of block for quinidine was significantly different between 2 and $20 \mathrm{mM} \mathrm{K}^{+}$, as well as between $\mathrm{K}^{+}$and $\mathrm{Cs}^{+}$, whereas cisapride block was unchanged (Barrows et al. 2009).
In reality, it is likely that both mechanisms may contribute, depending on the specific compound. In the current literature, mechanistic studies have generally sampled only small subsets of drugs, often because data has been generated using manual patch-clamp electrophysiology, which limits the throughput and scale of these investigations. To more confidently discern the mechanism by which altered $\mathrm{K}^{+}$affects drug potency, it is likely that studies of larger drug panels are required, which could be facilitated using high-throughput platforms such as automated patch-clamp or radioligand binding assays. For example, Diaz et al. used ${ }^{3} \mathrm{H}$ dofetilide binding assay to assess a panel of 56 compounds, showing that higher $\mathrm{K}^{+}$lead to reduced potency for some compounds, though increased potency for others (Diaz et al. 2004) - inconsistent with the broad trend reported in prior patch-clamp studies. However, in comparison with the gold standard of manual patch clamp, there was a greater than 5to sixfold difference between potencies measured in binding versus patch clamp for some compounds, with 6 of those compounds having greater than tenfold difference (Diaz et al. 2004). In resolving this question, the use of automated patch-clamp platforms, which combine throughput with gold standard electrophysiology, is likely the technology that will facilitate the scale and quality of information required for interpreting and predicting the clinical implications of $\mathrm{K}^{+}$ on hERG drug block and proarrhythmic risk into the future.

\section{Effects of divalent ions on drug-induced long QT syndrome}

\section{Clinical observations for altered serum divalent concentration}

Two divalent cations that are (i) present in human plasma at concentrations relevant for modification of hERG function and/or block, and (ii) have altered concentrations in pathophysiological states, are magnesium and calcium. In healthy patients, normal total plasma calcium concentration is in the range $2.2-2.55 \mathrm{mM}$, where concentrations outside of this range, typically lower, can contribute to QT prolongation and hence arrhythmic risk (Liu et al. 2019; Nijjer et al. 2010; Szymanski et al. 2013). However, free- or ionised-calcium concentrations are significantly lower (1.05-1.3 mM (Goldberg 2019)), due to binding to plasma proteins such as albumin (Labriola et al. 2009), making this the preferred clinical measurement in predicting prolongation of the QT interval (Kim et al. 2019) and a more suitable comparison for in vitro experiments than total $\mathrm{Ca}^{2+}$. Hypocalcaemia can be observed with renal insufficiency, parathyroid disease, reduced intake, acute pancreatitis, septic shock or other electrolyte disturbances, whereas hypercalcaemia is associated with hyperparathyroidism, vitamin D disturbances, endocrine disorders, 

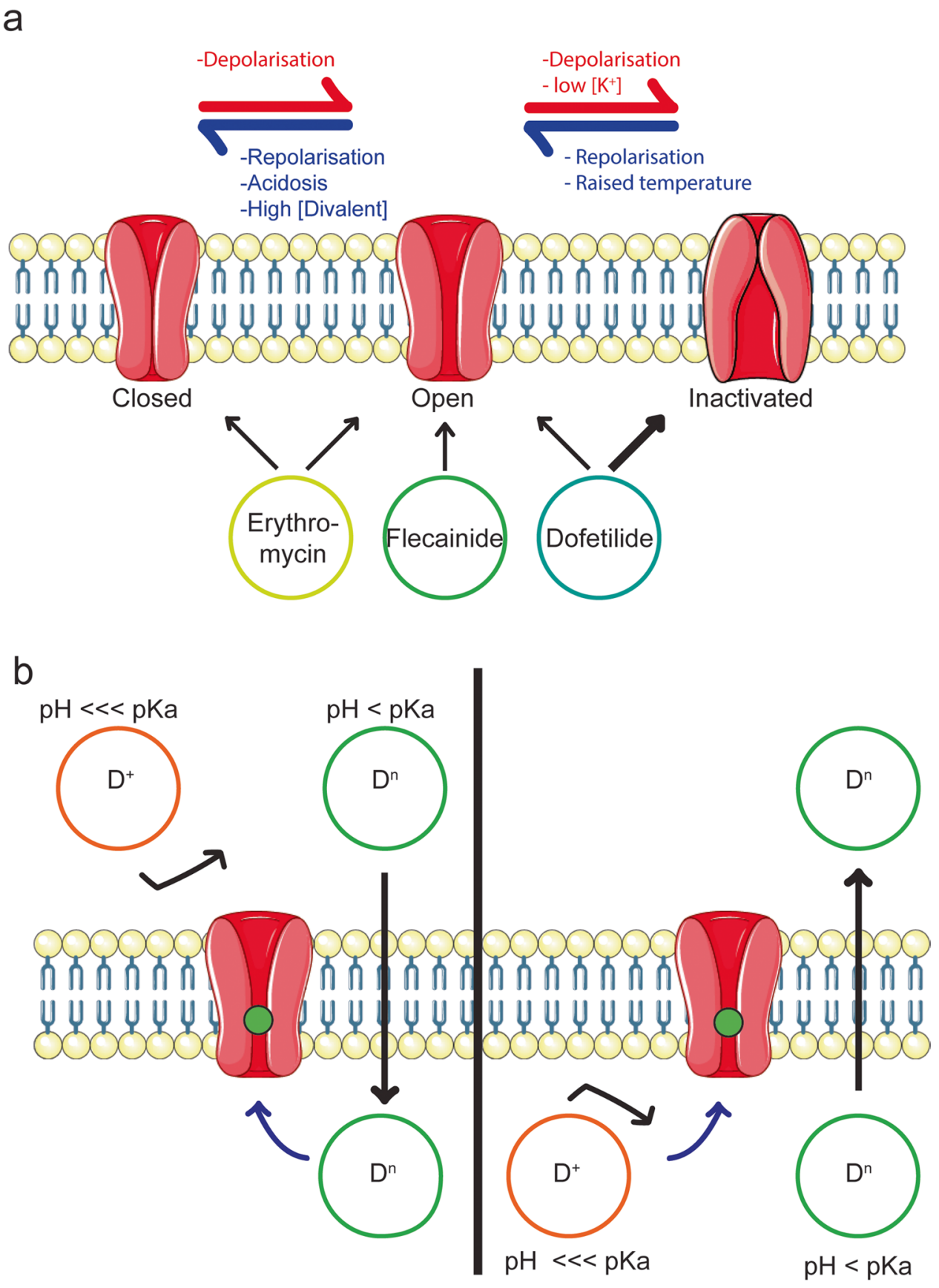

neoplastic disorders and many other malignancies (El-Sherif and Turitto 2011; Salzman 2018). For magnesium, the normal range is $0.7-0.95 \mathrm{mM}$, and while both hypomagnesemia and hypermagnesemia can result in QT interval prolongation (Topf and Murray 2003), their effects on electrophysiology are often hard to ascertain due to their frequent association with other electrolyte or electrophysiological abnormalities (Ayad et al. 2010; El-Sherif and Turitto 2011; Roden et al. 1986; Salzman 2018; Whang and Ryder 1990). Hypomagnesemia is common, especially in geriatric populations, and can occur due to decreased gastrointestinal uptake or renal loss, whereas hypermagnesemia is far rarer, especially outside of an obstetric population, given the large reserve of magnesium excretion potential the kidneys possess, often only occurring in the background of renal failure (El-Sherif and Turitto 2011; Topf and Murray 2003).

\section{Mechanism of divalent ion-dependent changes in hERG block}

While there is significant literature on the effect of divalent cations on cardiac electrophysiology and hERG channel 
4Fig. 2 Mechanisms of environmental effects on hERG and drug interactions. Some pathophysiological changes can have effects on the molecular mechanisms of hERG. a Represents a schematic showing hERG gating starting in the closed state (left), transitioning through to the open state (middle) by processes of depolarisation and transitioning again to an inactivated state (right) through depolarisation, with the reverse direction of these processes driven by repolarisation. Conditions that can increase deactivation, from open to closed state, include acidosis and high concentration of divalent ions, whereas conditions that could lead to a greater drive to inactivation includes low potassium ion concentration. Finally, raising temperature increases the threshold for hERG to exist in the open state. Beneath are drugs with state preference, with arrows indicated towards which hERG state they possess preferential binding towards, including dofetilide able to bind to open or inactivated state, with greater preference for the latter (Perrin et al. 2008; Wang et al. 2016; Yang et al. 2004), flecainide with open-state preference (Paul et al. 2002) and erythromycin with open or closed state preference (Guo et al. 2005). b Indicates the effect of acidosis on drug diffusion across the lipid bilayer. The site of binding is often located such that drug molecules require access from the intracellular side of the membrane and so must be able to cross the cell membrane. The left panel indicates drug administered extracellularly in the presence of extracellular acidosis. Where the local $\mathrm{pH}$ is far below the $\mathrm{pKa}$ of the drug molecule, a significant proportion of the drug molecule will become charged (D+) and hence unable to cross the lipid bilayer and reach the site of drug binding. Whereas when $\mathrm{pH}$ is only slightly below (or above) that of the molecules $\mathrm{pKa}$, a greater proportion is available in the neutral or uncharged state (Dn), which can cross the cell membrane and reach its site of action, indicated by the closed green circle. On the right shows similar conditions yet for intracellular drug application with intracellular acidosis. Here, the difference is that a greater amount of neutral drug molecule would lead to a greater diffusion out of the cell, and hence, less drug is available for channel block, where instead with a local $\mathrm{pH}$ far below the drug molecule's $\mathrm{pKa}$, the drug molecule becomes charged, and hence experiences trapping within the cell, and so a greater amount is available to block the channel. All channels, as well as lipid bilayer assets, were obtained from Servier Mediact Art (Servier 2021)

function, there are fewer comprehensive reports on divalent cation dependence of hERG drug block potency. Furthermore, the literature that does exist presents a somewhat inconsistent narrative. Increased extracellular $\mathrm{Mg}^{2+}$ has been shown to increase the potency of hERG block for multiple compounds (Po et al. 1999; TeBay et al. 2021), whereas reduced internal $\mathrm{Mg}^{2+}$ was found to reduce the potency of quinidine (Yang et al. 1997). Conversely, concentrations of extracellular $\mathrm{Ca}^{2+}$ between 0.1 and $10 \mathrm{mM}$ did not modify the block of either quinidine or cisapride (Barrows et al. 2009). Since there are suggestions that divalent ions could act as hERG/IKr blockers themselves, with binding sites identified within the hERG channel (Anumonwo et al. 1999; Ho et al. 1996, 1998, 1999), one potential mechanism could be that divalent ions together with hERG blocking drugs could result in an increased overall load of IKr inhibition (Po et al. 1999). Another potential explanation is that divalent ions regulate the deactivation kinetics of hERG, which could in turn affect drug dissociation and the degree to which some drugs exhibit "drug trapping" (Barrows et al. 2009). One factor that has confounded in vitro investigations in this area is the need for 1-2 $\mathrm{mM}$ concentrations of calcium in bath solutions for patch-clamp electrophysiology, which is critical for formation and maintenance of high-quality seals (Lin and Papazian 2007). As a result, investigations of the effects of variation in divalent ion concentrations in the physiological range are limited in these systems. This issue is particularly salient in automated high-throughput patch-clamp systems, where calcium fluoride seal enhancers are critical in establishing high-quality seals (Braun et al. 2021), meaning thorough investigation of the effects of divalent ions on drug block of hERG at large scale remains technically difficult. In addition to this practical challenge, there is also the issue of what is physiologically or clinically relevant. While observing the effects of wide ranges in concentration of divalent ions may be mechanistically interesting, calcium and particularly magnesium exist in narrow physiological ranges, meaning the clinical relevance of such studies are limited.

\section{Acidosis and alkalosis}

\section{Effect of acidosis and alkalosis on drug-induced QT prolongation}

Metabolic acidosis can increase the QT interval on the ECG (Yenigun et al. 2016) as well as lower the threshold for ventricular fibrillation. Such changes can become particularly problematic in the case of localised changes in $\mathrm{pH}$ surrounding ischemic regions of the heart, which produce heterogeneity in action potential duration and provide an electrical substrate for re-entry (Clayton and Holden 2005; Gebert et al. 1971; Podrid and Myerburg 2005; Surawicz 1985). Of specific relevance to this review, acidosis has also been reported as a comorbidity in cases of diLQTS (Riezzo et al. 2009). In relation to hERG channels, changes in $\mathrm{pH}$ can directly affect hERG function (Anumonwo et al. 1999; Jiang et al. 1999; Jo et al. 1999; Lin et al. 2005a; Shi et al. 2014; Van Slyke et al. 2012; Vereecke and Carmeliet 2000) as well as the molecular pharmacology of the drug channel interaction. In the latter case, early experiments showed that a reduction in $\mathrm{pH}$ to 6.8 could significantly reduce $\mathrm{hERG}$ block by dofetilide (West et al. 1997). Across numerous subsequent reports, there is broad consensus that extracellular acidification reduces $\mathrm{hERG}$ block by a range of compounds (Du et al. 2011; Lin et al. 2005a, b, 2008; TeBay et al. 2021; Thurner et al. 2014; Tschirhart and Zhang 2020; Wang et al. 2016; Zhang et al. 1999), with alkalisation enhancing drug block (Lin et al. 2005a; Thurner et al. 2014; Tschirhart and Zhang 2020; Zhang et al. 1999). There is however some complexity to this relationship since quite different results were seen when the extracellular solution was acidified using sodium acetate rather than hydrochloric acid. In this case, 
while lowered $\mathrm{pH}$ still reduced block by quinidine and azimilide, the potency of dofetilide was increased (Dong et al. 2004), with the authors suggesting this perhaps occurred because sodium acetate reduced the intracellular (as well as extracellular) pH (Dong et al. 2004). Furthermore, in experiments examining acidification of the intracellular space, while extracellular $\mathrm{pH}$ was maintained in the physiological range, dofetilide, flecainide and amiodarone's block was not diminished when the drugs were applied extracellularly (Du et al. 2011), while for ibogaine, intracellular application of the drug in the presence of intracellular acidification greatly increased the extent of block (Thurner et al. 2014).

\section{Mechanism of pH effects on hERG block}

Despite differences in drug class and chemical structure of compounds that block hERG, a common explanation for the effect of $\mathrm{pH}$ on drug potency has emerged, based on how charge on the functional groups of a drug molecule affects their partition coefficients and hence their ability to cross the cell membrane. For example, antimalarial drugs such as quinine and chloroquine are weak bases and can gain or lose protons from their amino groups depending on $\mathrm{pH}$ (Warhurst 1986). In their neutral form, these compounds are lipophilic, with a high partition coefficient $(\log \mathrm{P})$, and hence are able to cross the membrane to access their intracellular binding site. However, in more acidic environments, these molecules become protonated, more hydrophilic/lipophobic and less membrane permeable, limiting access to their intracellular binding site and reducing the observed degree of block (Warhurst 1986; Warhurst et al. 2003) (Fig. 1b). Consistent with this, it has been seen that a drug's potency to block hERG increases with lipophilicity, as measured by $\log \mathrm{P}$, or basicity, as measured by pKa (Kawai et al. 2011), while several studies of individual compounds also support this mechanism. For example, Zhang et al. calculated that for verapamil, with a $\mathrm{pKa}$ around $8.8,4 \%$ of molecules would exist in a neutral form at $\mathrm{pH} 7.4$, compared to $28 \%$ at $\mathrm{pH} 8.4$ and $0.4 \%$ at $\mathrm{pH} 6.4$, and observed a corresponding reduction in the potency of block as $\mathrm{pH}$ was decreased in vitro (Zhang et al. 1999). The authors also demonstrated that block by $\mathrm{N}$-methyl-verapamil, a permanently charged analogue of verapamil, was not sensitive to changes in $\mathrm{pH}$, confirming that the effect on block was specifically due to the charge on the drug molecule (Zhang et al. 1999). Similar explanations have also been posed for other drugs such as flecainide (Du et al. 2011), ibogaine (Thurner et al. 2014), fentanyl (Tschirhart and Zhang 2020) and hydroxychloroquine (TeBay et al. 2021) supporting the case that this is a common mechanism for the effect of $\mathrm{pH}$ on a drug's potency to bock ERG.

For some drug molecules, however, the picture can be more complicated. Dofetilide has multiple functional groups with different $\mathrm{pKa}$ values, including two methanesulfonamide groups, with pKa values of 9.0 and 9.6, as well as a nitrogen atom with a pKa of 7 , making it a zwitterion (Du et al. 2011). At a pH of 7.4, 2.5 and $0.6 \%$ of the methanesulfonamide moieties are charged, compared with $28.5 \%$ of amine groups (Du et al. 2011), while at $\mathrm{pH}$ 6.3, 0.2\% and $0.06 \%$ of the methanesulfonamide and $84 \%$ of the amine groups would be charged. Thus, the overall effect of acidic $\mathrm{pH}$ is a more charged, membrane impermeant molecule that shows reduced block of hERG at lower pH (Du et al. 2011). Other drugs have $\mathrm{pKa}$ values outside of the physiological/ pathophysiological range but can also exhibit modified potency of hERG block with respect to $\mathrm{pH}$. For example, flecainide, with a pKa of 9.3 , exists in $1.2 \%$ and $0.1 \%$ neutral form at $\mathrm{pH} 7.4$ and 6.3, respectively (a 12-fold difference), so still exhibits significant changes in observed potency between these $\mathrm{pH}$ values. Conversely, at the other extreme, amiodarone has a pKa of $5.6(98 \%$ neutral at $\mathrm{pH} 7.4$ and $83 \%$ at $\mathrm{pH} 6.3$ ) and is not sensitive to $\mathrm{pH}$ changes in the same range (Du et al. 2011). Finally, for some drugs such as ibogaine, this same mechanism can also result in internal accumulation of a drug molecule, where under low intracellular $\mathrm{pH}$ the drug molecule becomes ionised, and hence trapped within the cell, thus increasing the apparent potency of the drug (Fig. 2b) (Thurner et al. 2014).

In addition to the effect of $\mathrm{pH}$ via charge on the drug molecule, a further layer of nuance exists in understanding how environmental $\mathrm{pH}$ can alter a drug's potency to block hERG. In a similar manner to extracellular potassium, $\mathrm{pH}$ can also affect hERG channel function and hence influences state-specific drug-channel interactions. Specifically, acidosis is known to accelerate hERG deactivation, affecting the occupation of the open state at a given voltage (Anumonwo et al. 1999; Jiang et al. 1999; Jo et al. 1999; Vereecke and Carmeliet 2000) (Fig. 2a). In relation to this, the neutral form of dofetilide has been reported to preferentially bind to the open state of the hERG channel, while the cationic form preferentially binds to the inactivated state (Wang et al. 2016). Using molecular docking simulations, Wang et al. showed that as the channel transitions between open and inactivated states, there is reorientation of the key residues F656 and Y652 that form the drug binding site. Concomitant with this, cationic dofetilide can change confirmation, bringing its benzene rings closer in an event known as $\pi-\pi$ stacking, which allows the dofetilide molecule to bind to the channel and stabilise hERG in the inactivated state (Wang et al. 2016). Therefore, overall, a range of factors including the $\mathrm{pKa}$ of the compound, the $\mathrm{pH}$ of the extracellular versus intracellular environment, passage to the compounds intracellularly accessed binding site and the compound's state preference all contribute to the $\mathrm{pH}$ effect on hERG block in a compound-specific manner. Furthermore, in the physiologi$\mathrm{cal} /$ pathophysiological range of $\mathrm{pH}$, significant changes in 
hERG block, and hence QT prolongation, can occur, making this an important factor for consideration in relation to diLQTS.

\section{Temperature}

\section{Effect of febrile temperature on hERG block and drug-induced long QT syndrome}

Elevated/febrile body temperature, as a result of illness and infection, is known to alter or exacerbate diLQTS phenotypes in patients. Perhaps, most commonly, this occurs in association with the use of antibiotics such as vancomycin and gentamicin (Varriale and Ramaprasad 1995), or antifungals such as posaconazole (Panos et al. 2016), to treat infection. However, febrile temperatures are also associated with other pathophysiological conditions such as hypertension and diabetes mellitus in patients who may also be prescribed drugs with potential to prolong the QT interval such as enalapril and glyburide, respectively (Varriale and Ramaprasad 1995). In vitro studies that are specific to febrile versus physiological temperature are limited, with inconsistent reports across different drugs. Erythromycin, for example, has been shown to be a more potent hERG blocker at physiological $\left(37^{\circ} \mathrm{C}\right)$ as opposed to ambient $\left(22{ }^{\circ} \mathrm{C}\right)$ temperature, with further increased potency observed at febrile temperatures $\left(42{ }^{\circ} \mathrm{C}\right.$ ) (Guo et al. 2005). In contrast, for moxifloxacin, no significant change in potency was observed between physiological temperature and $42{ }^{\circ} \mathrm{C}$ (Alexandrou et al. 2006). Similarly, our investigations showed that febrile temperature significantly increased the potency of azithromycin as compared to physiological temperatures, while for chloroquine and hydroxychloroquine, potency was significantly reduced (TeBay et al. 2021). Further insights into the effect of temperature on hERG block can be gleaned from experiments performed at subfebrile temperatures, which are far more common in the literature. Lacerda et al. reported that physiological temperatures $\left(35^{\circ} \mathrm{C}\right)$ evoked only a slight change in potency for terfenadine and loratadine (increase or decrease respectively), with no significant changes observed for cisapride and erythromycin when compared to ambient temperature (Lacerda et al. 2001). Contrary to this, other studies report significant effects of temperature on block of hERG by erythromycin $(\sim$ sevenfold increase in potency) (Kirsch et al. 2004) - a difference perhaps is a result of the different voltage protocols used between the two studies. In relation to this, Kirsch noted that at $22{ }^{\circ} \mathrm{C}$, erythromycin did not reach steady state of block when employing a 2-s step pulse protocol with a 10-s interval, leading to an inaccurate estimate of $\mathrm{IC}_{50}$, while at physiological temperature, the true steady state was reached, because of the faster onset of block. This raises an important point that is equally applicable to any studies assessing hERG potency - that there is no "gold standard" protocol and the observed degree of block can be protocol specific. As a result, this potentially confounding factor should be considered in any comparison between studies, such as those described in this review. Overall, then it is clear from the literature that the effect of temperature on potency is compound specific, meaning consideration of the proarrhythmic risk associated with administration of potentially QT prolonging drugs to patients with fever needs to be made on a drug-by-drug basis.

\section{How does temperature modify potency of block?}

In a similar manner to kalaemic variation, experiments examining the temperature dependence of the potency of hERG block have suggested two potential mechanisms to explain temperature sensitivity: first, through modification of hERG channel function, particularly in relation to binding of state-dependent drugs, and, second, through direct effect on drug interaction with its binding site on the channel protein. In relation to the first of these, hERG electrophysiology displays complex temperature dependence, with increasing temperature causing a negative shift in the voltage dependence of activation, in concert with a positive shift in the voltage dependence of inactivation (Vandenberg et al. 2006), resulting in an overall increased occupancy of the open state at physiological voltages (Fig. 2a). For compounds that exhibit state-dependent binding, these temperature-dependent shifts in state occupancy therefore have potential to affect the measured potency of block. In this regard, Yao et al. investigated the effects of temperature on hERG block by probing state-dependent inhibition with various voltage protocols and temperatures. For astemizole, overall decreased potency was observed at higher temperature, with the greatest degree of block observed with a nonstate selective protocol, suggesting that astemizole is able to block multiple states of hERG (Yao et al. 2005). Both terfenadine and ketoconazole similarly showed little preference between protocols optimised for close- or open-state occupancy and, consistent with that, showed little change in potency at higher temperatures. Finally, while E-4031 exhibited open-state preference during ambient temperature recordings, no change in potency was observed at higher temperatures (Yao et al. 2005). The relationship between channel state occupancy, temperature and channel block is therefore complex and requires further experiments across a wider selection of compounds to fully resolve.

The second possible explanation for the effect of temperature on hERG potency - a direct impact of temperature on drug binding kinetics - has been probed using combinations of fast perfusion systems, voltage protocols and in silico modelling. Using ultra-fast solution exchange systems, Windley et al. were able to directly measure both the onset 
of block and washout of cisapride, showing that the kinetics of both drug binding and dissociation were temperature sensitive and that complex characteristics of kinetics at higher temperatures could be explained by an accumulation of drug in an intermediate, non-blocking state (termed an encounter complex). Furthermore, they showed that in the context of the cardiac action potential, these temperature-dependent effects on drug binding kinetics were important in predicting the degree of prolongation associated with hERG block (Windley et al. 2016). Following this, a study of a broader range of drugs including verapamil, cisapride, bepridil and terfenadine found that while increasing temperature accelerated the observed onset of block $\left(\tau_{\text {on }}\right)$ for all drugs, the temperature dependence of association and dissociation rates was compound specific (Windley et al. 2018). Furthermore, while there was no significant effect of temperature on measured potency in steady-state block assays, the alterations to the kinetic parameters alone still resulted in variable temperature dependence of the predicted degree of action potential prolongation for each of the drugs (Windley et al. 2018). Overall, this data therefore supports the need to consider the influence of temperature on the kinetics of drug block, even in the absence of changes to potency, in relation to diLQTS. Furthermore, since the effects of temperature appear to be compound specific, pharmacological screening data for use for risk prediction in diLQTS should where possible be acquired at physiological temperatures.

\section{Drug coadministration}

While most in vitro studies focus on the effect of a single environmental factor on hERG potency, the reality in relation to QT prolongation in the clinical setting is more complex. Patients are often administered multiple drugs with potential to prolong repolarisation, in the background of combinations of electrolyte disturbances and/or chronic disease states (Ayad et al. 2010; Digby et al. 2010). For example, in a study by Digby et al., subjects were prescribed on average $2.8 \mathrm{QT}$ prolonging drugs in the background of diseases including hypertension and dilated cardiomyopathy (Digby et al. 2011). Similarly, in a study of 48 patients hospitalised for TdP, the mean medication number per patient, including QT prolonging drugs in some instances, was 1.1, with electrolyte imbalances seen in $79 \%$ of patients (Lazzerini et al. 2018). This data therefore highlights the importance of considering how drugs might interact with each other, either directly or indirectly in understanding QT prolongation in patients.

Regarding direct drug effects, the simplest consideration is that of an additive effect on hERG block. Most drugs that block hERG are thought to share a common binding site formed by a network of aromatic residues in the vestibule of the channel (Kamiya et al. 2008; Stansfeld et al. 2006). Given this common binding site, a patient taking multiple QT prolonging agents could simply be considered to have an increased load of hERG channel block - so increasing their potential for QT prolongation and TdP. In patients, these additive effects have most often been reported in association with coadministration of antipsychotic drugs. Lin et al. reported a patient presenting with schizophrenia who was prescribed risperidone, amisulpride and haloperidol, leading to sudden cardiac arrest, where discontinuation of amisulpride leads to a gradually normalised QTc interval (Lin et al. 2009). In the same study, the authors also described a second patient who developed a QTc interval of $510 \mathrm{~ms}$ when co-administered amisulpride and flupenthixol, with neither agent alone producing concerning QT prolongation (Lin et al. 2009).

Aside from additive effects on hERG block, coadministration of drugs can also result in increased torsadogenicity via effects on drug metabolism. Increasing concentrations of berberine or clarithromycin have been shown to significantly inhibit activity of cytochrome P450 enzymes of the CYP3A family in vitro. Since this enzyme is a major metaboliser of many QT prolonging drugs, this reduction in CYP3A activity can lead to altered pharmacokinetics and hence a greater plasma concentration of either drug (Zhi et al. 2015). This link between inhibition of drug metabolism and proarrhythmia has been observed across multiple studies including reports that ketoconazole, erythromycin, diltiazem, itraconazole and grapefruit juice — all inhibitors of cytochrome P450 enzymes - have resulted in increased serum concentration of terfenadine, halofantrine and cisapride, leading to QT prolongation and TdP (Charbit et al. 2002; Paris et al. 1994; Pohjola-Sintonen et al. 1993; Rajput et al. 2010; Thomas et al. 1998). This phenomenon has also been detected in larger cohorts where coadministration of ketoconazole with domperidone was found to triple the plasma concentration of domperidone, exacerbating QTc prolongation to clinically significant levels, over and above that observed for either agent alone (Boyce et al. 2012).

Systemic effects induced by other drugs have also been seen to modify the risk profile of QT prolonging compounds. For example, Roden et al. described cases where hypokalaemia caused by potassium-depleting diuretics were found to exacerbate quinidine-induced QT prolongation (Roden et al. 1986), while incidences of hypomagnesemia caused by protein pump inhibitor usage, in combination with QT prolonging medications such as ceftriaxone or disopyramide, were shown to trigger TdP (Lazzerini et al. 2018). Finally, another case described a patient treated with prednisolone for myasthenia gravis precipitating atrial fibrillation, which was in turn treated with disopyramide. The disopyramide administration resulted in worsening myasthenia gravis, leading to respiratory failure and serum disturbances including 
alkalosis and hypokalaemia, which together precipitated TdP (Hirose et al. 2008). Together, these cases demonstrate that regardless of the mechanism of their interaction, the simultaneous presence of multiple hERG blocking agents, and their interaction with systemic factors such as electrolytes, have clear potential to increase proarrhythmic risk, and patients should be monitored appropriately when QT prolonging medicines are co-administered.

\section{Conclusions}

In order to understand or predict the occurrence of druginduced QT prolongation and TdP in patients, it is clear that risk allocation is far more complicated than a static label assigned to individual drugs. Rather, a range of pathophysiological factors associated with disease states as well as coadministration with other drugs need to be considered when prescribing and managing the risk of therapeutics with potential to prolong the QT interval. While significant literature exists describing how factors such as $\mathrm{pH}$, fever and kalaemic variation affect potency to block hERG, there are still gaps in our knowledge regarding the mechanisms of these effects, which may be better addressed via studies on more extensive drug libraries that are now feasible as a result of the increased use of high-throughput automated patchclamp screening platforms. Furthermore, incorporation of data from these large-scale screens into population models of cardiac electrophysiology (TeBay et al. 2021; Varshneya et al. 2021) will help us better understand the relationships between a drug's ion channel blocking potency, the effect of environmental modifiers, genetic background and risk of TdP.

Author contribution Clifford TeBay and Monique Windley contributed to the conception and design. Clifford TeBay performed the literature review and wrote the first draft. All authors critically revised the manuscript. All authors approved the final manuscript.

Funding Open Access funding enabled and organized by CAUL and its Member Institutions. Clifford TeBay is supported through an Australian Government Research Training Program Scholarship. Monique Windley is supported by an Australian National Health and Medical Research Council project grant to Adam Hill (GNT1164518).

\section{Declarations}

Ethics approval and consent to participate. Not applicable.

Consent for publication. Not applicable.

Conflict of interest The authors declare no competing interests.
Open Access This article is licensed under a Creative Commons Attribution 4.0 International License, which permits use, sharing, adaptation, distribution and reproduction in any medium or format, as long as you give appropriate credit to the original author(s) and the source, provide a link to the Creative Commons licence, and indicate if changes were made. The images or other third party material in this article are included in the article's Creative Commons licence, unless indicated otherwise in a credit line to the material. If material is not included in the article's Creative Commons licence and your intended use is not permitted by statutory regulation or exceeds the permitted use, you will need to obtain permission directly from the copyright holder. To view a copy of this licence, visit http://creativecommons.org/licenses/by/4.0/.

\section{References}

Alexandrou AJ, Duncan RS, Sullivan A, Hancox JC, Leishman DJ, Witchel HJ, Leaney JL (2006) Mechanism of hERG K+ channel blockade by the fluoroquinolone antibiotic moxifloxacin. Br J Pharmacol 147:905-916. https://doi.org/10.1038/sj.bjp. 0706678

Alfano G, Ferrari A, Fontana F, Perrone R, Mori G, Ascione E, Magistroni R, Venturi G, Pederzoli S, Margiotta G, Romeo M, Piccinini F, Franceschi G, Volpi S, Flatoni M, Ciusa G, Bacca E, Tutone M, Raimondi A, Menozzi M, Franecschini E, Cuomo G, Orlando G, Santoro A, Di Gaetano M, Puzzolante C, Carli F, Bedini A, Milic J, Meschiari M, Mussini C, Cappelli G, Guaraldi G (2021) Hypokalemia in patients with COVID-19. Clin Exp Nephrol 25:401-409. https://doi.org/10.1007/s10157-020-01996-4

Anumonwo JM, Horta J, Delmar M, Taffet SM, Jalife J (1999) Proton and zinc effects on HERG currents. Biophys J 77:282-298. https://doi.org/10.1016/S0006-3495(99)76889-X

Aslam W, Lamb CR, Ali N (2021) Torsades de pointes in SARSCoV-2 (COVID-19) pneumonia: medicine reconciliation and careful monitoring of QTc interval may help prevent cardiac complications. BMJ Case Rep 14:e239963. https://doi.org/10. 1136/bcr-2020-239963

Ayad RF, Assar MD, Simpson L, Garner JB, Schussler JM (2010) Causes and management of drug-induced long QT syndrome. Proc (bayl Univ Med Cent) 23:250-255. https://doi.org/10. 1080/08998280.2010.11928628

Barrows B, Cheung K, Bialobrzeski T, Foster J, Schulze J, Miller A (2009) Extracellular potassium dependency of block of HERG by quinidine and cisapride is primarily determined by the permeant ion and not by inactivation. Channels (austin) 3:239-248. https://doi.org/10.4161/chan.3.4.9254

Birda CL, Kumar S, Bhalla A, Sharma N, Kumari S (2018) Prevalence and prognostic significance of prolonged QTc interval in emergency medical patients: a prospective observational study. Int J Crit Illn Inj Sci 8:28-35. https://doi.org/10.4103/IJCIIS. IJCIIS_59_17

Boyce MJ, Baisley KJ, Warrington SJ (2012) Pharmacokinetic interaction between domperidone and ketoconazole leads to QT prolongation in healthy volunteers: a randomized, placebo-controlled, double-blind, crossover study. Br J Clin Pharmacol 73:411-421. https://doi.org/10.1111/j.1365-2125.2011.04093.x

Braun N, Friis S, Ihling C, Sinz A, Andersen J, Pless SA (2021) High-throughput characterization of photocrosslinker-bearing ion channel variants to map residues critical for function and pharmacology. PLoS Biol 19:e3001321. https://doi.org/10. 1371/journal.pbio.3001321

Busch AE, Eigenberger B, Jurkiewicz NK, Salata JJ, Pica A, Suessbrich H, Lang F (1998) Blockade of HERG channels by the class III antiarrhythmic azimilide: mode of action. Br J Pharmacol 123:23-30. https://doi.org/10.1038/sj.bjp.0701575 
Charbit B, Becquemont L, Lepere B, Peytavin G, Funck-Brentano C (2002) Pharmacokinetic and pharmacodynamic interaction between grapefruit juice and halofantrine. Clin Pharmacol Ther 72:514-523. https://doi.org/10.1067/mcp.2002.128148b

Clayton RH, Holden AV (2005) Dispersion of cardiac action potential duration and the initiation of re-entry: a computational study. Biomed Eng Online 4:11. https://doi.org/10.1186/ 1475-925X-4-11

Darpö B (2001) Spectrum of drugs prolonging QT interval and the incidence of torsades de pointes. Eur Heart J Suppl 3:K70K80. https://doi.org/10.1016/S1520-765X(01)90009-4

Darpö B (2007) Detection and reporting of drug-induced proarrhythmias: room for improvement. Europace 9(Suppl 4):iv23-iv36. https://doi.org/10.1093/europace/eum168

Delaunois A, Abernathy M, Anderson WD, Beattie KA, Chaudhary KW, Coulot J, Gryshkova V, Hebeisen S, Holbrook M, Kramer J, Kuryshev Y, Leishman D, Lushbough I, Passini E, Redfern WS, Rodriguez B, Rossman EI, Trovato C, Wu C, Valentin J (2021) Applying the CiPA approach to evaluate cardiac proarrhythmia risk of some antimalarials used off-label in the first wave of COVID-19. Clin Transl Sci 14:1133-1146. https://doi. org/10.1111/cts.13011

Diaz GJ, Daniell K, Leitza ST, Martin RL, Su Z, McDermott JS, Cox BF, Gintant GA (2004) The [3H]dofetilide binding assay is a predictive screening tool for hERG blockade and proarrhythmia: comparison of intact cell and membrane preparations and effects of altering [K+]o. J Pharmacol Toxicol Methods 50:187-199. https://doi.org/10.1016/j.vascn.2004.04.001

Digby G, Machaalany J, Malik P, Methot M, Simpson CS, Redfearn D, Baranchuk A (2010) Multifactorial QT interval prolongation. Cardiol J 17:184-188. https://doi.org/10.1155/2014/213842

Digby GC, Perez Riera AR, Barbosa Barros R, Simpson CS, Redfearn DP, Methot M, Femenia F, Baranchuk A (2011) Acquired long QT interval: a case series of multifactorial QT prolongation. Clin Cardiol 34:577-582. https://doi.org/10.1002/clc.20945

Dong DL, Li Z, Wang HZ, Du ZM, Song WH, Yang BF (2004) Acidification alters antiarrhythmic drug blockade of the ether-a-gogo-related gene (HERG) channels. Basic Clin Pharmacol Toxicol 94:209-212. https://doi.org/10.1111/j.1742-7843.2004.pto94 0503.X

Du CY, El Harchi A, Zhang YH, Orchard CH, Hancox JC (2011) Pharmacological inhibition of the hERG potassium channel is modulated by extracellular but not intracellular acidosis. J Cardiovasc Electrophysiol 22:1163-1170. https://doi.org/10.1111/j. 1540-8167.2011.02060.x

Echt DS, Liebson PR, Mitchell LB, Peters RW, Obias-Manno D, Barker AH, Arensberg D, Baker A, Friedman L, Greene HL et al (1991) Mortality and morbidity in patients receiving encainide, flecainide, or placebo. The Cardiac Arrhythmia Suppression Trial. N Engl J Med 324:781-788. https://doi.org/10.1056/NEJM1 99103213241201

El-Sherif N, Turitto G (2011) Electrolyte disorders and arrhythmogenesis. Cardiol J 18:233-245

Gebert G, Benzing H, Strohm M (1971) Changes in the interstitial $\mathrm{pH}$ of dog myocardium in response to local ischemia, hypoxia, hyper- and hypocapnia, measured continuously by means of glass microelectrodes. Pflügers Archiv 329:72-81. https://doi.org/10. 1007/BF00586901

Goldberg D (2019) Calcium, Ionized. Laboratory Medicine. https:// www.emedicine.medscape.com/article/2087469. Accessed $27 / 12 / 2021$

Guo J, Zhan S, Lees-Miller JP, Teng G, Duff HJ (2005) Exaggerated block of hERG $(\mathrm{KCNH} 2)$ and prolongation of action potential duration by erythromycin at temperatures between 37 degrees $\mathrm{C}$ and 42 degrees C. Heart Rhythm 2:860-866. https://doi.org/10. 1016/j.hrthm.2005.04.029
Guo J, Massaeli H, Xu J, Jia Z, Wigle JT, Mesaeli N, Zhang S (2009) Extracellular $\mathrm{K}+$ concentration controls cell surface density of IKr in rabbit hearts and of the HERG channel in human cell lines. J Clin Invest 119:2745-2757. https://doi.org/10.1172/JCI39027

Guo J, Wang T, Yang T, Xu J, Li W, Fridman MD, Fisher JT, Zhang S (2011) Interaction between the cardiac rapidly (IKr) and slowly (IKs) activating delayed rectifier potassium channels revealed by low $\mathrm{K}+$-induced hERG endocytic degradation. J Biol Chem 286:34664-34674. https://doi.org/10.1074/jbc.M111.253351

Hirose K, Yamaguchi H, Oshima Y, Choraku M, Hirono A, Takamori N, Tamura K (2008) Severe respiratory failure and torsades de pointes induced by disopyramide in a patient with myasthenia gravis. Intern Med 47:1703-1708. https://doi.org/10.2169/inter nalmedicine.47.0976

Ho WK, Earm YE, Lee SH, Brown HF, Noble D (1996) Voltage- and time-dependent block of delayed rectifier $\mathrm{K}+$ current in rabbit sino-atrial node cells by external $\mathrm{Ca} 2+$ and $\mathrm{Mg} 2+$. J Physiol 494(Pt 3):727-742. https://doi.org/10.1113/jphysiol.1996.sp021 528

Ho WK, Kim I, Lee CO, Earm YE (1998) Voltage-dependent blockade of HERG channels expressed in Xenopus oocytes by external $\mathrm{Ca} 2+$ and Mg2+. J Physiol 507(Pt 3):631-638. https://doi.org/ 10.1111/j.1469-7793.1998.631bs.x

Ho WK, Kim I, Lee CO, Youm JB, Lee SH, Earm YE (1999) Blockade of HERG channels expressed in Xenopus laevis oocytes by external divalent cations. Biophys J 76:1959-1971. https://doi. org/10.1016/S0006-3495(99)77355-8

ICH S7B, HHS, F.D.A (2005) International conference on harmonisation; guidance on S7B nonclinical evaluation of the potential for delayed ventricular repolarization (QT interval prolongation) by human pharmaceuticals; availability. Notice Fed Register 70:61133-61134

Jiang M, Dun W, Tseng GN (1999) Mechanism for the effects of extracellular acidification on HERG-channel function. Am J Physiol 277:H1283-H1292. https://doi.org/10.1152/ajpheart.1999.277.4. H1283

Jo SH, Youm JB, Kim I, Lee CO, Earm YE, Ho WK (1999) Blockade of HERG channels expressed in Xenopus oocytes by external H+. Pflugers Arch 438:23-29. https://doi.org/10.1007/s0042 40050875

Kamiya K, Niwa R, Morishima M, Honjo H, Sanguinetti MC (2008) Molecular determinants of hERG channel block by terfenadine and cisapride. J Pharmacol Sci 108:301-307. https://doi.org/10. 1254/jphs.08102FP

Kannankeril PJ, Norris KJ, Carter S, Roden DM (2011) Factors affecting the degree of QT prolongation with drug challenge in a large cohort of normal volunteers. Heart Rhythm 8:1530-1534. https:// doi.org/10.1016/j.hrthm.2011.03.042

Kawai Y, Tsukamoto S, Ito J, Akimoto K, Takahashi M (2011) A risk assessment of human ether-a-go-go-related gene potassium channel inhibition by using lipophilicity and basicity for drug discovery. Chem Pharm Bull (tokyo) 59:1110-1116. https://doi.org/10. 1248/cpb.59.1110

Kim ED, Watt J, Tereshchenko LG, Jaar BG, Sozio SM, Kao WHL, Estrella MM, Parekh RS (2019) Associations of serum and dialysate electrolytes with QT interval and prolongation in incident hemodialysis: the predictors of arrhythmic and cardiovascular risk in end-stage renal disease (PACE) study. BMC Nephrol 20:133. https://doi.org/10.1186/s12882-019-1282-5

Kirsch GE, Trepakova ES, Brimecombe JC, Sidach SS, Erickson HD, Kochan MC, Shyjka LM, Lacerda AE, Brown AM (2004) Variability in the measurement of hERG potassium channel inhibition: effects of temperature and stimulus pattern. J Pharmacol Toxicol Methods 50:93-101. https://doi.org/10.1016/j.vascn.2004.06.003

Labriola L, Wallemacq P, Gulbis B, Jadoul M (2009) The impact of the assay for measuring albumin on corrected ('adjusted') calcium 
concentrations. Nephrol Dial Transplant 24:1834-1838. https:// doi.org/10.1093/ndt/gfn747

Lacerda AE, Kramer J, Shen KZ, Thomas D, Brown AM (2001) Comparison of block among cloned cardiac potassium channels by non-antiarrhythmic drugs. Eur Heart J Suppl 3:K23-K30. https:// doi.org/10.1016/S1520-765X(01)90003-3

Lazzerini PE, Bertolozzi I, Finizola F, Acampa M, Natale M, Vanni F, Fulceri R, Gamberucci A, Rossi M, Giabbani B, Caselli M, Lamberti I, Cevenini G, Laghi-Pasini F, Capecchi PL (2018) Proton pump inhibitors and serum magnesium levels in patients with torsades de pointes. Front Pharmacol 9:363. https://doi.org/ 10.3389/fphar.2018.00363

Lee W, Mann SA, Windley MJ, Imtiaz MS, Vandenberg JI, Hill AP (2016) In silico assessment of kinetics and state dependent binding properties of drugs causing acquired LQTS. Prog Biophys Mol Biol 120:89-99. https://doi.org/10.1016/j.pbiomolbio.2015. 12.005

Lee W, Windley MJ, Perry MD, Vandenberg JI, Hill AP (2019) Protocol-dependent differences in IC50 values measured in human ether-à-go-go-related gene assays occur in a predictable way and can be used to quantify state preference of drug binding. Mol Pharmacol 95:537-550. https://doi.org/10.1124/mol.118.115220

Limberis JT, Su Z, Cox BF, Gintant GA, Martin RL (2006) Altering extracellular potassium concentration does not modulate drug block of human ether-a-go-go-related gene (hERG) channels. Clin Exp Pharmacol Physiol 33:1059-1065. https://doi.org/10. 1111/j.1440-1681.2006.04487.x

Lin MC, Papazian DM (2007) Differences between ion binding to eag and HERG voltage sensors contribute to differential regulation of activation and deactivation gating. Channels (austin) 1:429-437. https://doi.org/10.4161/chan.1.6.5760

Lin C, Cvetanovic I, Ke X, Ranade V, Somberg J (2005a) A mechanism for the potential proarrhythmic effect of acidosis, bradycardia, and hypokalemia on the blockade of human ether-a-go-go-related gene (HERG) channels. Am J Ther 12:328-336. https://doi.org/ 10.1097/01.mjt.0000143698.53038.1b

Lin C, Ke X, Cvetanovic I, Ranade V, Somberg J (2005b) The influence of extracellular acidosis on the effect of IKr blockers. $\mathrm{J}$ Cardiovasc Pharmacol Ther 10:67-76. https://doi.org/10.1177/ 107424840501000108

Lin J, Guo J, Gang H, Wojciechowski P, Wigle JT, Zhang S (2005c) Intracellular $\mathrm{K}+$ is required for the inactivation-induced highaffinity binding of cisapride to HERG channels. Mol Pharmacol 68:855-865. https://doi.org/10.1124/mol.105.012278

Lin C, Ke X, Cvetanovic I, Ranade V, Somberg J (2007) The effect of high extracellular potassium on IKr inhibition by anti-arrhythmic agents. Cardiology 108:18-27. https://doi.org/10.1159/00009 5596

Lin C, Ke X, Ranade V, Somberg J (2008) Extracellular acidification and hyperkalemia induce changes in HERG inhibition by ibutilide. Cardiology 110:209-216. https://doi.org/10.1159/00011 1932

Lin Y, Sun IW, Liu SI, Chen CY, Hsu CC (2009) QTc prolongation during concurrent treatment with depot antipsychotics and high-dose amisulpride: a report of 2 cases. J Intern Med Taiwan 20:544-549

Lin Y, Yu H, Liu F, Chen C, Zhang Y, Wang B, Yang Y, Liu Y, Zhang L, Xia Y (2020) Hospitalized cancer patients with acquired long QT syndrome-a matched case-control study. Cardiooncology 6:3. https://doi.org/10.1186/s40959-020-0057-2

Lippi G, South AM, Henry BM (2020) Electrolyte imbalances in patients with severe coronavirus disease 2019 (COVID-19). Ann Clin Biochem 57:262-265. https://doi.org/10.1177/00045 63220922255

Liu P, Han D, Sun X, Tan H, Wang Z, Liu C, Zhang Y, Li B, Sun C, Shi R, Li G (2019) Prevalence and risk factors of acquired long QT syndrome in hospitalized patients with chronic kidney disease. J Investig Med 67:289-294. https://doi.org/10.1136/ jim-2018-000798

Makkar RR, Fromm BS, Steinman RT, Meissner MD, Lehmann MH (1993) Female gender as a risk factor for torsades de pointes associated with cardiovascular drugs. JAMA 270:2590-2597. https://doi.org/10.1001/jama.270.21.2590

Melgari D, Du C, El Harchi A, Zhang Y, Hancox JC (2014) Suppression of the hERG potassium channel response to premature stimulation by reduction in extracellular potassium concentration. Physiol Rep 2:e12165. https://doi.org/10.14814/phy2.12165

Mergenthaler J, Haverkamp W, Huttenhofer A, Skryabin BV, Musshoff U, Borggrefe M, Speckmann EJ, Breithardt G, Madeja M (2001) Blocking effects of the antiarrhythmic drug propafenone on the HERG potassium channel. Naunyn Schmiedebergs Arch Pharmacol 363:472-480. https://doi.org/10.1007/s002100000392

Nijjer S, Ghosh AK, Dubrey SW (2010) Hypocalcaemia, long QT interval and atrial arrhythmias. BMJ Case Rep 2010:bcr0820092216. https://doi.org/10.1136/bcr.08.2009.2216

Pan L, Mu M, Yang P, Sun Y, Wang R, Yan J, Li P, Hu B, Wang J, Hu C, Jin Y, Niu X, Ping R, Du Y, Li T, Xu G, Hu Q, Tu L (2020) Clinical characteristics of COVID-19 patients with digestive symptoms in Hubei, China: a descriptive, cross-sectional, multicenter study. Am J Gastroenterol 115:766-773. https://doi.org/ 10.14309/ajg.0000000000000620

Panos G, Velissaris D, Karamouzos V, Matzaroglou C, Tylianakis M (2016) Long QT syndrome leading to multiple cardiac arrests after posaconazole administration in an immune-compromised patient with sepsis: an unusual case report. Am J Case Rep 17:295-300. https://doi.org/10.12659/ajcr.896946

Paris DG, Parente TF, Bruschetta HR, Guzman E, Niarchos AP (1994) Torsades de pointes induced by erythromycin and terfenadine. Am J Emerg Med 12:636-638. https://doi.org/10.1016/07356757(94)90029-9

Paul AA, Witchel HJ, Hancox JC (2002) Inhibition of the current of heterologously expressed HERG potassium channels by flecainide and comparison with quinidine, propafenone and lignocaine. Br J Pharmacol 136:717-729. https://doi.org/10.1038/ sj.bjp.0704784

Perrin MJ, Kuchel PW, Campbell TJ, Vandenberg JI (2008) Drug binding to the inactivated state is necessary but not sufficient for high-affinity binding to human ether-à-go-go-related gene channels. Mol Pharmacol 74:1443-1452. https://doi.org/10.1124/ mol.108.049056

Po SS, Wang DW, Yang IC, Johnson JP Jr, Nie L, Bennett PB (1999) Modulation of HERG potassium channels by extracellular magnesium and quinidine. J Cardiovasc Pharmacol 33:181-185. https://doi.org/10.1097/00005344-199902000-00002

Podrid PJ, Myerburg RJ (2005) Epidemiology and stratification of risk for sudden cardiac death. Clin Cardiol 28:I3-11. https://doi.org/ $10.1002 /$ clc.4960281303

Pohjola-Sintonen S, Viitasalo M, Toivonene L, Neuvonen P (1993) Torsades de pointes after terfenadine-itraconazole interaction. BMJ 306:186. https://doi.org/10.1136/bmj.306.6871.186

Rajput SK, Singh JN, Sharma SS (2010) Evaluation of terfenadine and ketoconazole-induced QT prolongation in conscious telemetered guinea pigs. Pharmacol Rep 62:683-688. https://doi.org/10.1016/ S1734-1140(10)70325-X

Riezzo I, Centini F, Neri M, Rossi G, Spanoudaki E, Turillazzi E, Fineschi V (2009) Brugada-like EKG pattern and myocardial effects in a chronic propofol abuser. Clin Toxicol (phila) 47:358-363. https://doi.org/10.1080/15563650902887842

Roden DM (2004) Drug-induced prolongation of the QT interval. N Engl J Med 350:1013-1022. https://doi.org/10.1056/NEJMr a032426 
Roden DM, Viswanathan PC (2005) Genetics of acquired long QT syndrome. J Clin Invest 115:2025-2032. https://doi.org/10.1172/ JCI25539

Roden DM, Woosley RL, Primm RK (1986) Incidence and clinical features of the quinidine-associated long QT syndrome: implications for patient care. Am Heart J 111:1088-1093. https://doi.org/10. 1016/0002-8703(86)90010-4

Salzman A (2018) Electrolyte imbalance + normal ranges and disturbances for common electrolytes. Online CPD. https://www. ausmed.com.au/cpd/articles/normal-electrolyte-levels. Accessed $13 / 08 / 2021$

Schoonmaker FW, Osteen RT, Greenfield JC Jr (1966) Thioridazine (mellaril)-induced ventricular tachycardia controlled with an artificial pacemaker. Ann Intern Med 65:1076-1078. https://doi.org/ 10.7326/0003-4819-65-5-1076

Selzer A, Wray HW (1964) Quinidine syncope. Paroxysmal ventricular fibrillation occurring during treatment of chronic atrial arrhythmias. Circulation 30:17-26. https://doi.org/10.1161/01.CIR.30.1. 17

Servier LL (2021) SMART-Servier Medical Art. Servier. https://smart. servier.com/. Accessed 23/11/2021

Shah RR (2005) Drug-induced QT interval prolongation-regulatory guidance and perspectives on hERG channel studies. Novartis Found Symp 266:251-80

Shi YP, Cheng YM, Van Slyke AC, Claydon TW (2014) External protons destabilize the activated voltage sensor in hERG channels. Eur Biophys J 43:59-69. https://doi.org/10.1007/ s00249-013-0940-y

Singh S, Zoble RG, Yellen L, Brodsky MA, Feld GK, Berk M, Billing CB Jr (2000) Efficacy and safety of oral dofetilide in converting to and maintaining sinus rhythm in patients with chronic atrial fibrillation or atrial flutter: the symptomatic atrial fibrillation investigative research on dofetilide (SAFIRE-D) study. Circulation 102:2385-2390. https://doi.org/10.1161/01.CIR.102.19. 2385

Stansfeld PJ, Sutcliffe MJ, Mitcheson JS (2006) Molecular mechanisms for drug interactions with hERG that cause long QT syndrome. Expert Opin Drug Metab Toxicol 2:81-94. https://doi.org/10. 1517/17425255.2.1.81

Stevens JS, Moses AA, Nickolas TL, Husain SA, Mohan S (2021) Increased mortality associated with hypermagnesemia in severe COVID-19 illness. Kidney 360(2):1087-1094. https://doi.org/ 10.34067/KID.0002592021

Stork D, Timin EN, Berjukow S, Huber C, Hohaus A, Auer M, Hering $S$ (2007) State dependent dissociation of HERG channel inhibitors. Br J Pharmacol 151:1368-1376. https://doi.org/10.1038/ sj.bjp.0707356

Surawicz B (1985) Ventricular fibrillation. J Am Coll Cardiol 5:43B54B. https://doi.org/10.1016/S0735-1097(85)80526-X

Szymanski FM, Karpinski G, Platek AE, Puchalski B, Filipiak KJ (2013) Long QT interval in a patient after out-of-hospital cardiac arrest with hypocalcaemia, undergoing therapeutic hypothermia. Am J Emerg Med 31(1722):e1-3. https://doi.org/10.1016/j.ajem. 2013.07.026

TeBay C, McArthur JR, Mangala M, Kerr N, Heitmann S, Perry MD, Windley MJ, Vandenberg JI, Hill AP (2021) Pathophysiological metabolic changes associated with disease modify the proarrhythmic risk profile of drugs with potential to prolong repolarisation. Br J Pharmacol. https://doi.org/10.1111/bph.15757

Thomas AR, Chan LN, Bauman JL, Olopade CO (1998) Prolongation of the QT interval related to cisapride-diltiazem interaction. Pharmacotherapy 18:381-385. https://doi.org/10.1002/j.18759114.1998.tb03866.x

Thouta S, Lo G, Grajauskas L, Claydon T (2018) Investigating the state dependence of drug binding in hERG channels using a trapped-open channel phenotype. Sci Rep 8:4962. https://doi. org/10.1038/s41598-018-23346-x

Thurner P, Stary-Weinzinger A, Gafar H, Gawali VS, Kudlacek O, Zezula J, Hilber K, Boehm S, Sandtner W, Koenig X (2014) Mechanism of hERG channel block by the psychoactive indole alkaloid ibogaine. J Pharmacol Exp Ther 348:346-358. https:// doi.org/10.1124/jpet.113.209643

Topf JM, Murray PT (2003) Hypomagnesemia and hypermagnesemia. Rev Endocr Metab Disord 4:195-206. https://doi.org/10.1023/A 1022950321817

Tschirhart JN, Zhang S (2020) Fentanyl-induced block of hERG channels is exacerbated by hypoxia, hypokalemia, alkalosis, and the presence of hERG1b. Mol Pharmacol 98:508-517. https://doi. org/10.1124/mol.119.119271

Van Slyke AC, Cheng YM, Mafi P, Allard CR, Hull CM, Shi YP, Claydon TW (2012) Proton block of the pore underlies the inhibition of hERG cardiac $\mathrm{K}+$ channels during acidosis. Am J Physiol Cell Physiol 302:C1797-C1806. https://doi.org/10. 1152/ajpcell.00324.2011

Vandenberg JI, Varghese A, Lu Y, Bursill JA, Mahaut-Smith MP, Huang CL (2006) Temperature dependence of human ethera-go-go-related gene K+ currents. Am J Physiol Cell Physiol 291:C165-C175. https://doi.org/10.1152/ajpcell.00596.2005

Vandenberg JI, Perry MD, Perrin MJ, Mann SA, Ke Y, Hill AP (2012) hERG $\mathrm{K}(+)$ channels: structure, function, and clinical significance. Physiol Rev 92:1393-1478. https://doi.org/10. 1152/physrev.00036.2011

Varriale P, Ramaprasad S (1995) Septic cardiomyopathy as a cause of long QT syndrome. J Electrocardiol 28:327-329. https://doi org/10.1016/S0022-0736(05)80051-2

Varshneya M, Irurzun-Arana I, Campana C, Dariolli R, Gutierrez A, Pullinger TK, Sobie EA (2021) Investigational treatments for COVID-19 may increase ventricular arrhythmia risk through drug interactions. CPT Pharmacometrics Syst Pharmacol 10:100-107. https://doi.org/10.1002/psp4.12573

Vereecke J, Carmeliet E (2000) The effect of external pH on the delayed rectifying $\mathrm{K}+$ current in cardiac ventricular myocytes. Pflugers Arch 439:739-751. https://doi.org/10.1007/s0042 49900243

Wang S, Morales MJ, Liu S, Strauss HC, Rasmusson RL (1997) Modulation of HERG affinity for E-4031 by [K+]o and C-type inactivation. FEBS Lett 417:43-47. https://doi.org/10.1016/S00145793(97)01245-3

Wang Y, Guo J, Perissinotti LL, Lees-Miller J, Teng G, Durdagi S, Duff HJ, Noskov SY (2016) Role of the pH in state-dependent blockade of hERG currents. Sci Rep 6:32536. https://doi.org/ 10.1038/srep32536

Warhurst DC (1986) Antimalarial drugs: mode of action and resistance. J Antimicrob Chemother 18(Suppl B):51-9. https://doi.org/10. 1093/jac/18.Supplement_B.51

Warhurst DC, Steele JC, Adagu IS, Craig JC, Cullander C (2003) Hydroxychloroquine is much less active than chloroquine against chloroquine-resistant Plasmodium falciparum, in agreement with its physicochemical properties. J Antimicrob Chemother 52:188193. https://doi.org/10.1093/jac/dkg319

West PD, Martin DK, Bursill JA, Wyse KR, Campbell TJ (1997) Modulation of the electrophysiologic actions of E-4031 and dofetilide by hyperkalemia and acidosis in rabbit ventricular myocytes. J Cardiovasc Pharmacol Ther 2:205-212. https://doi.org/10.1177/ 107424849700200307

Whang R, Ryder KW (1990) Frequency of hypomagnesemia and hypermagnesemia. Requested vs routine. JAMA 263:3063-3064. https://doi.org/10.1001/jama.1990.03440220087036

Windley MJ, Mann SA, Vandenberg JI, Hill AP (2016) Temperature effects on kinetics of KV11.1 drug block have important 
consequences for in silico proarrhythmic risk prediction. Mol Pharmacol 90:1-11. https://doi.org/10.1124/mol.115.103127

Windley MJ, Lee W, Vandenberg JI, Hill AP (2018) The temperature dependence of kinetics associated with drug block of hERG channels Is compound-specific and an important factor for proarrhythmic risk prediction. Mol Pharmacol 94:760-769. https:// doi.org/10.1124/mol.117.111534

Yang T, Snyders DJ, Roden DM (1997) Rapid inactivation determines the rectification and $[\mathrm{K}+]$ o dependence of the rapid component of the delayed rectifier $\mathrm{K}+$ current in cardiac cells. Circ Res 80:782-789. https://doi.org/10.1161/01.RES.80.6.782

Yang BF, Xu DH, Xu CQ, Li Z, Du ZM, Wang HZ, Dong DL (2004) Inactivation gating determines drug potency: a common mechanism for drug blockade of HERG channels. Acta Pharmacol Sin 25:554-560

Yao JA, Du X, Lu D, Baker RL, Daharsh E, Atterson P (2005) Estimation of potency of HERG channel blockers: impact of voltage protocol and temperature. J Pharmacol Toxicol Methods 52:146153. https://doi.org/10.1016/j.vascn.2005.04.008

Yenigun EC, Aypak C, Turgut D, Aydin MZ, Dede F (2016) Effect of metabolic acidosis on QT intervals in patients with chronic kidney disease. Int J Artif Organs 39:272-276. https://doi.org/ 10.5301/ijao.5000509

Yu H, Zhang L, Liu J, Liu Y, Kowey PR, Zhang Y, Chen Y, Wei Y, Gao L, Li H, Du J, Xia Y (2017) Acquired long QT syndrome in hospitalized patients. Heart Rhythm 14:974-978. https://doi. org/10.1016/j.hrthm.2017.03.014
Zequn Z, Yujia W, Dingding Q, Jiangfang L (2021) Off-label use of chloroquine, hydroxychloroquine, azithromycin and lopinavir/ ritonavir in COVID-19 risks prolonging the QT interval by targeting the hERG channel. Eur J Pharmacol 893:173813. https:// doi.org/10.1016/j.ejphar.2020.173813

Zhang S, Zhou Z, Gong Q, Makielski JC, January CT (1999) Mechanism of block and identification of the verapamil binding domain to HERG potassium channels. Circ Res 84:989-998. https://doi. org/10.1161/01.RES.84.9.989

Zhi D, Feng PF, Sun JL, Guo F, Zhang R, Zhao X, Li BX (2015) The enhancement of cardiac toxicity by concomitant administration of berberine and macrolides. Eur J Pharm Sci 76:149-155. https://doi.org/10.1016/j.ejps.2015.05.009

Zhou F, Yu T, Du R, Fan G, Liu Y, Liu Z, Xiang J, Wang Y, Song B, Gu X, Guan L, Wei Y, Li H, Wu X, Xu J, Tu S, Zhang Y, Chen $\mathrm{H}$, Cao B (2020) Clinical course and risk factors for mortality of adult inpatients with COVID-19 in Wuhan, China: a retrospective cohort study. Lancet 395:1054-1062. https://doi.org/10.1016/ S0140-6736(20)30566-3

Publisher's note Springer Nature remains neutral with regard to jurisdictional claims in published maps and institutional affiliations. 